\title{
La crisis en la Unión Europea: el caso de Cataluña (2017)
} The Crisis in the European Union: The Case of Catalonia (2017)

\section{Damián Bil}

Centro de Estudios Urbanos y Regionales (CEUR), Consejo Nacional de Investigaciones Científicas y Técnicas (CONICET), Argentina https://orcid.org/0000-0002-7054-2927

damibil@gmail.com

\section{RESUMEN}

Este trabajo pretende analizar someramente un evento de lo que consideramos la crisis estructural de la zona euro: el conflicto independentista en Cataluña (2017). Nos concentraremos en el análisis del fenómeno económico, entendiéndolo como consecuencia de la crisis del capital de largo plazo. A partir del análisis de variables económicas agregadas —en particular referentes a la producción e industria, finanzas públicas e ingreso de hogares y de trabajadores - y de la organización productiva, y mediante el análisis de la relación de Cataluña con el resto del España y de la eurozona, intentaremos discutir la noción de una supuesta "opresión nacional" en la perspectiva de las transformaciones ocurridas en esta región luego de la crisis de 2008-09.

Palabras claves: crisis, Unión Europea, Cataluña, deuda pública, historia económica.

Códigos JEL: N24, N34, N44. 


\section{ABSTRACT}

This paper seeks to briefly analyze an event that we consider the structural crisis of the Euro zone: the independence conflict in Catalonia (2017). The research will focus on the analysis of the economic phenomenon, which is understood as a consequence of the long-term capital crisis. From the analysis of aggregate economic variables -in particular regarding production and industry, public finances, and income of households and workers - and the productive organization, we will try to discuss the notion of an alleged "national oppression" in the perspective of the transformations that occurred after the 2008-09 crisis in Catalonia by approaching the relationship of this region with the rest of the Spain and the eurozone.

Keywords: Crisis, European Union, Catalonia, public debt, economic history.

JEL Codes: N24, N34, N44. 


\section{INTRODUCCIÓN}

En 2008-09 se produjo una crisis en la economía capitalista a nivel global que se conoció como la crisis de las subprime. Medido en términos de paridad del poder adquisitivo (en dólares de 2015), según la Organización para la Cooperación y el Desarrollo Económicos (OCDE), el PBI de EE. UU. cayó 2,5 \%, mientras que el de la zona núcleo de la Unión Europea se redujo un 4,5\%. Por su parte, Japón retrocedió 5,4\%. Algunos autores, como Harvey (2016), sugieren que existe una multicausalidad de elementos que explican este fenómeno y tienden a englobarlo más que nada como una típica crisis financiera (Dumenil, 2012). En oposición a esta perspectiva, otra corriente de autores señala que este episodio fue el último - por lo menos hasta la desaceleración global de 2018 y de la pandemia del COVID-19, que puso en jaque a la economía mundial- de una larga serie de sucesos que de forma periódica azotan la acumulación de capital desde la década de los años 70. Esta crisis se habría iniciado a partir de una erosión de la tasa de ganancia en el núcleo de la acumulación capitalista (EE. UU. y Europa), lo que abrió un ciclo descendente del nivel de beneficio de la inversión de capital. Esta situación propició la generación de "burbujas" de capital ficticio que fueron estallando desde ese momento hasta la actualidad, sin poder recomponer un crecimiento sostenido y sano de la acumulación. Dichas burbujas se manifestaron en crisis específicas, como la del petróleo de 1973, la de la deuda en el tercer mundo a comienzos de la década de los 80, los "efectos" en los años 90 (tequila, vodka, arroz), la crisis de comienzos de los 2000 ("punto com", o la crisis argentina), la señalada de la burbuja inmobiliaria en 2008 (particularmente grave en España por la dinámica de crecimiento previa) y probablemente la coyuntura actual. La burguesía, a nivel mundial, aun no pudo recomponer condiciones como regían en el boom de posguerra. Por ese motivo, las crisis se profundizan y plantean distintos escenarios políticos que complejizan el panorama. Este análisis es compartido por varios autores, con ligeras diferencias metodológicas o de periodización de la etapa (Chakri, 2014; Freeman, 2016; Kliman, 2015; Maito, 2014; Moseley, 2013; Roberts, 2009, 2016; Sartelli, 2006).

En cuanto a la recesión de 2008-09, sin duda, la situación afectó al corazón de la acumulación mundial (EE. UU. y Europa). Son recordadas las diversas crisis de las hipotecas en EE. UU. y España (donde el PBI cayó casi 4 \%), por citar los casos más resonantes y que generaron mayores debates. En varias 
regiones se resintieron los indicadores de crecimiento económico, incluida la Argentina.

A nivel mundial, la "salida" de ese atolladero se dio por diversas vías. Una de las centrales fue una política monetaria aún más laxa en diferentes países, con la renovada expansión de capital ficticio mediante la política de inyectar circulante en la economía ("quantitative easing" en EE. UU.) a su vez que se disminuían las tasas de interés a valores cercanos a $0 \%$, o directamente a ese valor, como en Japón. Varios países, como veremos en el caso español, incrementaron su endeudamiento público como forma de sostener la acumulación. Ese proceso evidencia el pasaje a la fase "estatal" de la crisis.

En esta perspectiva, el presente artículo se propone analizar brevemente un evento de la crisis orgánica (política, social y económica) en la zona euro, a saber: el conflicto independentista en Cataluña (2017). En esta ocasión, nos concentraremos en el análisis del fenómeno económico, entendiéndolo como consecuencia de la crisis del capital de largo plazo (iniciada en la década de los 70 y acelerada con estertores posteriores, como el de 2008). Intentaremos discutir la noción de una supuesta "opresión nacional" a partir del estudio de la organización productiva de la Comunidad en cuestión y su relación con el resto del país, bajo la perspectiva de las transformaciones ocurridas luego de la crisis 2008-09. Trabajamos para ello series vinculadas a ingresos y salarios de la población, producción industrial (en particular de la industria automotriz), finanzas públicas (ingresos, deuda y otros) y agregados macroeconómicos (PBI), entre otros factores. Con ello, se busca reconstruir la evolución de ciertos indicadores para observar cómo se procesa en el aspecto económico la crisis.

En estos abordajes, dejamos para futuros trabajos la indagación de las transformaciones sociales y políticas de la región, lo que incluye las distintas fuerzas en pugna, el fenómeno de las movilizaciones desde 2010-11 (que dio lugar al movimiento de los "Indignados"), entre otros elementos. Para el lector interesado en revisar estos fenómenos, señalamos algunas referencias en el acápite siguiente.

El objetivo es entender el fenómeno como parte de esa crisis irresuelta de largo plazo, así como las estrategias, en el plano económico, que el capital se da para preparar la salida. Nos remitimos a fuentes oficiales (oficinas de estadísticas de la Unión Europea, España y de la Generalitat), organismos nacionales o internacionales como la Oficina de Estadísticas Laborales de 
EE. UU. (BLS) y la Organización Internacional de Constructores de Automóviles (OICA), información empresarial (por ejemplo, de la cámara automotriz española, ANFAC) y aportes de otros autores.

\section{APORTES PREVIOS SOBRE LA TEMÁTICA}

Antes de avanzar con el presente estudio, se hace necesario revisar los aportes existentes que pueden ser relevantes para el trabajo. Existe una larga lista de estudios sobre los efectos de la crisis que se abre luego de 2008-09 en la Unión Europea (UE), en sus diferentes aspectos: en el plano de la estructura económica, en los efectos sobre la sociedad (en particular el impacto sobre el empleo, los desahucios inmobiliarios, la pauperización de ciertas capas de la población y la migración recibida de otros países, como los principales) y en las consecuencias políticas. Aquí, reseñaremos brevemente algunos textos que nos brindan elementos para retomar nuestra indagación.

En primer término, como expresamos previamente, no vamos a tratar ni el fenómeno de la movilización política, los principios que levantan, ni el proceso de crisis institucional del Estado español en el período de estudio, puesto que son elementos que exceden el objetivo de este documento. Existen varios trabajos que reponen tanto las bases históricas, teóricas y filosóficas del nacionalismo catalán (Fontana, 2014; Molinero \& Ysás, 2014) como las pugnas recientes en torno a las posiciones de distintos actores políticos de la sociedad catalana y la presión por la realización de consultas (Llorca-Asensi, 2015; Serra et al., 2018), así como también análisis jurídicos detallados sobre la viabilidad constitucional de los argumentos independentistas (Ruipérez-Alamillo, 2013). Recomendamos remitirse a estos textos para complementar este aspecto de la problemática a trabajar.

Por su parte, los aspectos económicos de la crisis y sus efectos sobre España fueron trabajados por varios autores desde diferentes perspectivas teóricas. Existen avances que describen la dinámica general del fenómeno (Mateo-Tomé, 2019; Taguas, 2013; Torrero-Mañas, 2008) a partir del peso de la burbuja inmobiliaria en la crisis (Alonso-Pérez \& Furió-Blasco, 2010; García-Montalvo, 2009); los efectos de la crisis sobre estructuras como el mercado laboral o la salud de la población, donde los estudios muestran cómo la crisis profundizó la fragmentación previa de la clase obrera entre los estables, los temporarios y los trabajadores en el paro (Antenas \& Vivas, 2014; Rocha \& Aragón, 2012; Sanromá-Meléndez, 2012; Verd-Pericás \& 
López-Andeu, 2016); las transformaciones de los flujos migratorios (Cebrián et al., 2010; Domingo-i-Valls et al., 2014; Gutiérrez \& Delclós, 2014); las consecuencias sobre el gasto público y las áreas sociales de la administración (Araceli-Mateos, 2013; Gallo \& Gené-Badia, 2015), entre muchos otros avances. Estos trabajos aportan elementos valiosos para nuestro objetivo. Por ejemplo, desde la geografía económica se estudió el patrón de localización poblacional y la dinámica de la burbuja inmobiliaria pre y postcrisis. Ciertos estudios encuentran un elevado boom demográfico en la región catalana en el período que va de comienzos de los años 90 hasta 2007 como efecto de la disponibilidad de viviendas. Sin embargo, la explosión de la crisis alteró esta dinámica, con un freno al crecimiento poblacional y al proceso de rejuvenecimiento. El paro aumenta y la renta de los hogares disminuye en términos reales, aunque el proceso es más atenuado en la ciudad de Barcelona y en municipios dispersos con presencia de trabajadores calificados o de propietarios (burguesía o pequeña burguesía). Así mismo, el efecto sobre sectores medios de la población con hipotecas de viviendas es severo (López-Villanueva et al., 2017).

En este punto, la dinámica particular de la crisis fue descrita por varios autores. Entre ellos, Buendía (2018) señala que el denominado "milagro económico" español entre mediados de los 90 y 2007 fue en realidad un espejismo. Ese impulso económico se basó en el endeudamiento masivo, flujo que fue a parar mayormente a la inversión en construcción. Cuando la deuda no pudo renovarse, luego de la quiebra de Lehman Brothers en 2008, se desató la crisis. El motor de la dinámica de esos años, la construcción, se detuvo y arrastró a todo el país a un descalabro profundo, con una severa destrucción de empleos, el deterioro de las cuentas públicas y un déficit fiscal. Las finanzas públicas colapsaron debido a que incrementaron los gastos por el aumento del número de seguros de desempleo, los rescates bancarios y una política expansiva del gobierno al inicio de la crisis. Al mismo tiempo, cayeron los ingresos por la retracción de la construcción y otros sectores. Las políticas de austeridad que se implementaron luego empeoraron el panorama.

Se buscó entonces recuperar competitividad por la vía de la reducción del costo laboral, para lo cual se sucedieron reformas laborales en 2010 y 2012, medidas que permitieron abaratar y facilitar despidos, descentralizar la negociación colectiva y reducir beneficios a los trabajadores. Así mismo, se dispuso una reducción del gasto público mediante el congelamiento 
salarial y despidos en la nómina del Estado, un gradual incremento de la edad jubilatoria de 65 a 67 años, el aumento en los años de cotización para acceder a las pensiones más elevadas, restricciones para acceder a la jubilación anticipada, reducción en la cartilla de medicamentos cubiertos por la sanidad pública, tercerización en el sector salud, eliminación de algunos servicios educativos estatales y el recorte en subvenciones y privatizaciones de áreas estatales (como en aeropuertos y lotería). Como consecuencia, cayó el salario real y aumentó el riesgo de pobreza aún para los trabajadores activos. En cuanto al hábitat, el boom inmobiliario tuvo como consecuencia, luego de la crisis, una bolsa de vivienda vacía e inacabada que se constituyó como la más grande de la historia de España, a la vez que se dificultaba el acceso a la misma (Gutiérrez \& Delclós, 2015). En Cataluña, se produjo un proceso de exclusión, segregación y desigualdad ciudadana, mientras que los bancos acumularon vivienda a partir de desahucios como forma de apropiar renta urbana, movilizando capitales que no contaban con otro espacio de valorización (Gutiérrez \& Delclós, 2017; Gutiérrez \& Vives-Miró, 2018).

La recesión también repercutió a nivel de las comunidades autónomas, que sufrieron las mismas restricciones presupuestarias y de acceso al crédito que el Estado central. En Cataluña, se perdieron en el quinquenio 20082012 más de 567.000 puestos de trabajo. También se produjeron recortes en salud y otras áreas del Estado, a pesar de ser una de las comunidades que más recibe de ciertas áreas del estado central (como el Ministerio de Fomento). Esto sirvió a las autoridades catalanas para agitar el "España nos roba", con el que buscaron negociar mejores condiciones fiscales ante Madrid, como afirman Guzmán-Ramírez y Quiroga-Riviere (2013). Estos autores señalan que en un comienzo la demanda de autonomía no estaba en el centro del descontento que empezaba a surgir en la región. Sin embargo, luego de los sucesos del 15M (2011) y de sucesivas movilizaciones, tanto Artur Mas (presidente de la Generalitat con popularidad en caída) como las fuerzas políticas que se disputan el gobierno de la comunidad con ese discurso debían mantenerlo. En efecto, en primera instancia, el movimiento de Indignados ante la situación económica plantea un difuso programa cuyo eje es el rechazo a la clase política, a las finanzas. Según el especialista Josep Antenas, los reclamos desarticulados políticamente fueron asumidos por sectores del nacionalismo catalán para aprovechar la situación en un contexto de malestar, transmitiendo "la sensación de que el Estado español es un buque con vías de agua cada vez más difíciles de contener, con un capitán al mando 
debilitado, y un proyecto fallido a la deriva" (2012, p. 269). Otros estudios indican que las demandas nacionalistas surgen cuando la crisis fiscal llegó a las comunidades; si bien el colapso se da en 2008, por el sistema de financiación autonómica, el mismo se produjo algo más tarde a nivel regional. Durante el boom, debido a los ingresos de la recaudación y del auge económico, muchas colectividades aumentaron los gastos en servicios públicos (salud, educación, etc.). Cuando se produce la recesión, se encuentran con una estructura de gastos rígida y una caída en los ingresos que dificulta hacer frente al gasto corriente. En ese esquema, Cataluña fue una de las comunidades que más expandió el gasto público y el endeudamiento durante el período 1994-2007. Durante la crisis, fue de las comunidades que menos ajustó, recurriendo al incremento de su deuda (que es aproximadamente $50 \%$ mayor al del promedio del resto de las comunidades). Pero ello absorbió mayores niveles de ingreso disponible para el pago de intereses en detrimento del gasto social, tensionando la situación económica y social. De ahí, la demanda por mejor tratamiento fiscal y financiero, buscando retener recursos en la crisis (Feito-Higuerela, 2014).

Clua-Losada (2018) también asocia la coyuntura social a la crisis económica. La misma se transforma en política en 2011, cuando estallan movimientos de protesta frente a las políticas austeridad. Ello en el contexto de la quiebra del proceso de europeización y de las normas democráticas abiertas con el pacto de 1978. De todas formas, esa estructura heredada de la transición aún actúa como contención política, ya que despolitizó las formas de oposición y las incorporó al estado (incluidos sindicatos y organismos vecinales).

\section{Cataluña, 2017}

Veamos entonces cuál es el trasfondo económico del conflicto por la independencia. El 1 de octubre de 2017 se realizó el referéndum de carácter vinculante (o "1-0") en la Generalidad de Cataluña con el objeto de presionar por una secesión. Cabe señalar que estos comicios fueron objetados por la Comisión Europea. Además, estuvieron plagados de irregularidades, aun dentro del marco legal burgués. El resultado final arrojó $90 \%$ de los votos válidos por el "sí" (más de 2 millones) contra 7,8 \% por el "no" (177.500) y cerca de $2 \%$ en blanco (44.900). La participación fue de $43 \%$, diez puntos por debajo de lo que la Unión Europea reconoció como piso en otros casos (Montenegro y Serbia, por ejemplo). Por otro lado, el 
referéndum y lo que se produjo alrededor estuvo teñido de escándalo: localidades donde se registraron más votos que habilitados para sufragar, la represión a las protestas por parte del gobierno del Partido Popular (PP), los cruces verbales entre Mariano Rajoy y Carles Puidgemont, la declaración de independencia que duró solo 56 segundos, entre otros. Esto es evidencia de la profunda crisis en la, hasta el momento, quinta economía de la UE. En este punto, consideramos que la disputa no tiene nada de progresivo para las masas trabajadoras ni de España, en general, ni de Cataluña, en particular, sino que esconde la forma en que diferentes fracciones burguesas buscan resolverla. Analizamos a continuación cómo fue presentado el conflicto por buena parte de la izquierda (no solo en España sino también en la Argentina), para luego revisar la estructura económica de la región en el contexto nacional y los efectos de la crisis.

\section{En defensa del enemigo}

Si bien existieron voces disidentes en la izquierda, la mayor parte de las fuerzas en lugar de denunciar la maniobra de las fracciones capitalistas que incitan el regionalismo más rancio, como ocurre en otros países con regiones ricas, se plegó a apoyar a los líderes de la Generalitat. Incluso, les recriminaron una supuesta traición por no ir más a fondo. Suponiendo progresiva la lucha de una entelequia como el "pueblo" catalán, en el cual se unifican tanto los dueños de La Caixa, de Seat o de Editorial Planeta con los trabajadores, se lanzaron a una ahistórica proclama contra la monarquía (como si aún perviviera la nobleza feudal) y el centralismo de Madrid, asumiendo sin ningún fundamento que la independencia catalana provocaría la conformación de una república soviética.

Se cometen a nuestro entender tres errores: (i) se analiza la situación con un esquema que ya no existe en la realidad (como si fuera la España de 1936); (ii) se fomenta el particularismo en la forma de regionalismo, en detrimento de lo universal, en esa conversión hacia los dogmas posmodernos que lamentablemente la izquierda adopta desde la caída del Muro de Berlín; y (iii) fundamentalmente se pierde el anclaje del análisis de clase para abordar el fenómeno desde el prisma superficial de una supuesta "cuestión nacional" (una crítica detallada en este mismo sentido en Guerrero, 2006). De esta manera, y adelantándonos a las conclusiones, se convierten en furgón de cola de la fracción capitalista catalana y su personal político de turno, que presionan para reacomodarse dentro de la estructura fiscal del Estado español, para que "el pato" de la crisis la paguen otras fracciones, 
amenazando con la secesión. Similar a las plataformas de movimientos regionalistas por el estilo, como el Yes California en EE. UU., O sul e o meu país en Brasil o la Lega Nord en Italia. Con fórmulas para cuidar las apariencias (la "autodeterminación", el Ilamado a una "federación de repúblicas socialistas ibéricas"), no consiguen articular una posición independiente, subordinando lo "nacional" al interés de clase. La izquierda argentina no desentonó con estas posiciones, apoyando en mayor o menor grado la iniciativa.

Ahora bien, lo que hay que dilucidar es si efectivamente la región sufre un proceso de opresión por parte del Estado central y si la independencia es una medida progresiva para los trabajadores. Analicemos en profundidad el primer término de esta formulación, lo que nos permitirá señalar algunos hilos de interpretación para el segundo.

\section{ESPAÑA EN EL CONCIERTO EUROPEO}

Examinemos con más detenimiento la economía española y la participación de Cataluña en ella, con el objeto de dilucidar si existe algún tipo de traba económica por parte de la "monarquía" sobre el pueblo catalán. Como señalamos, abordaremos aquí solamente la estructura y las consecuencias económicas de la crisis.

España es, por su PBI, la $16^{\circ}$ economía del mundo y la $5^{\circ}$ en la UE. Representa un 7,5\% del producto de ese espacio económico de 28 países. En comparación con otras potencias, en términos de su producto tiene un $35 \%$ del tamaño de Alemania y es la mitad de Francia o el Reino Unido, es un $7 \%$ de la economía de los EE. UU. y una décima parte de China. Frente a otras regiones, es dos terceras partes la economía de Brasil y 2,2 veces más grande que la de Argentina. El PBI por persona ocupada es 1,8 \% mayor al del promedio de la UE. Como en casi cualquier parte del mundo, este país acumula (es decir, apropian plusvalor) los principales grupos económicos internacionales. También hay capitales que operan a nivel mundial con base en España; los que más facturaron en 2016 fueron Telefónica, los grupos Santander y BBVA y la petrolera Repsol.

España cuenta con 46,53 millones de habitantes, de los cuales 8 de cada 10 reside en ciudades. En 2016, la población aumentó por primera vez desde 2011; esto fue producto de la inmigración, dado que su crecimiento vegetativo es prácticamente nulo. El nivel de ingreso y los salarios se ubican cerca del rango de Italia, por debajo de los principales países de la UE (25\% 
menos que en Alemania y Francia), pero muy por encima de la considerada "periferia" (Europa del Este, Portugal, Grecia, los Balcanes y otros países).

A nivel de la producción, su principal exportación son los vehículos. En 2016 2,4 millones de unidades fueron despachadas, lo que representó un $15 \%$ de lo que exportó el país. España es desde 2009 el segundo fabricante de la UE, superando a Francia. Se ubica en los últimos años entre el $8^{\circ}$ y $9^{\circ}$ puesto a nivel mundial (intercambiando esa posición con Brasil). El sector, en su conjunto, aporta casi el $20 \%$ del valor total de exportaciones del país (ANFAC, 2017). Le siguen las autopartes, los medicamentos, los combustibles y productos agropecuarios como la carne de cerdo, el aceite de oliva, citrus y vinos (figura 1).

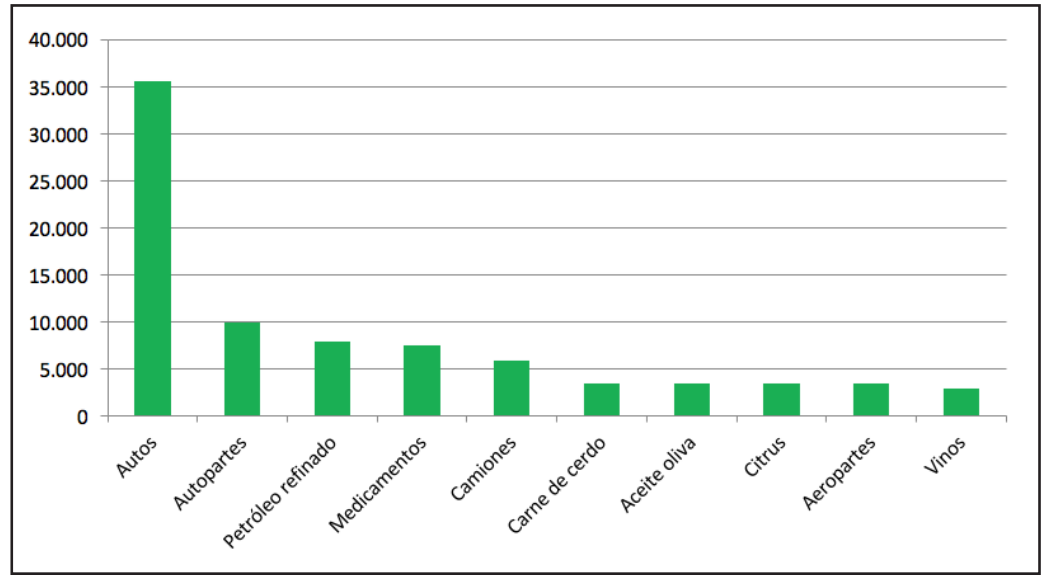

Sus principales clientes son regionales (Francia con $15 \%$ y Alemania con $12 \%$ ). Importa casi lo mismo: crudo y gas ( $9^{\circ}$ importador mundial), vehículos y partes, medicamentos, textiles, electrodomésticos, computadoras y alimentos. Sus principales proveedores son Alemania (14 \%), Francia (11\%) y China (9\%). Cabe destacar que la balanza comercial española es deficitaria, promediando en 2008-2016 un saldo anual de -118.000 millones de euros (figura 2).

Como señalamos en el estado de la cuestión, la crisis de 2008 golpeó duramente a la economía española. Su PBI se redujo 7 \% entre 2008 y 2012. Recién en 2016 recuperó los niveles de las vísperas de la crisis (figura 3). Esto significó una caída mayor y una recuperación algo más tardía que la del promedio de la UE, lejos de la evolución de las tres principales economías del bloque (Alemania, Reino Unido y Francia).
Figura 1.

Principales productos de exportación de España en 2016 (cifras en millones de dólares)

Fuente: Atlas Comercio Internacional MTI (2016). 
Figura 2.

Balanza comercial de España 1997-2016 (cifras en miles de millores de dólares corrientes

Fuente: elaboración propia con base en Atlas Comercio Internacional MTI (2016).

Figura 3. Evolución del PBI en las principales economías de la UE y promedio de los 28 países entre 2005 y 2019 $(2005=1)$

Fuente: elaboración propia con base en OCDE Stats.
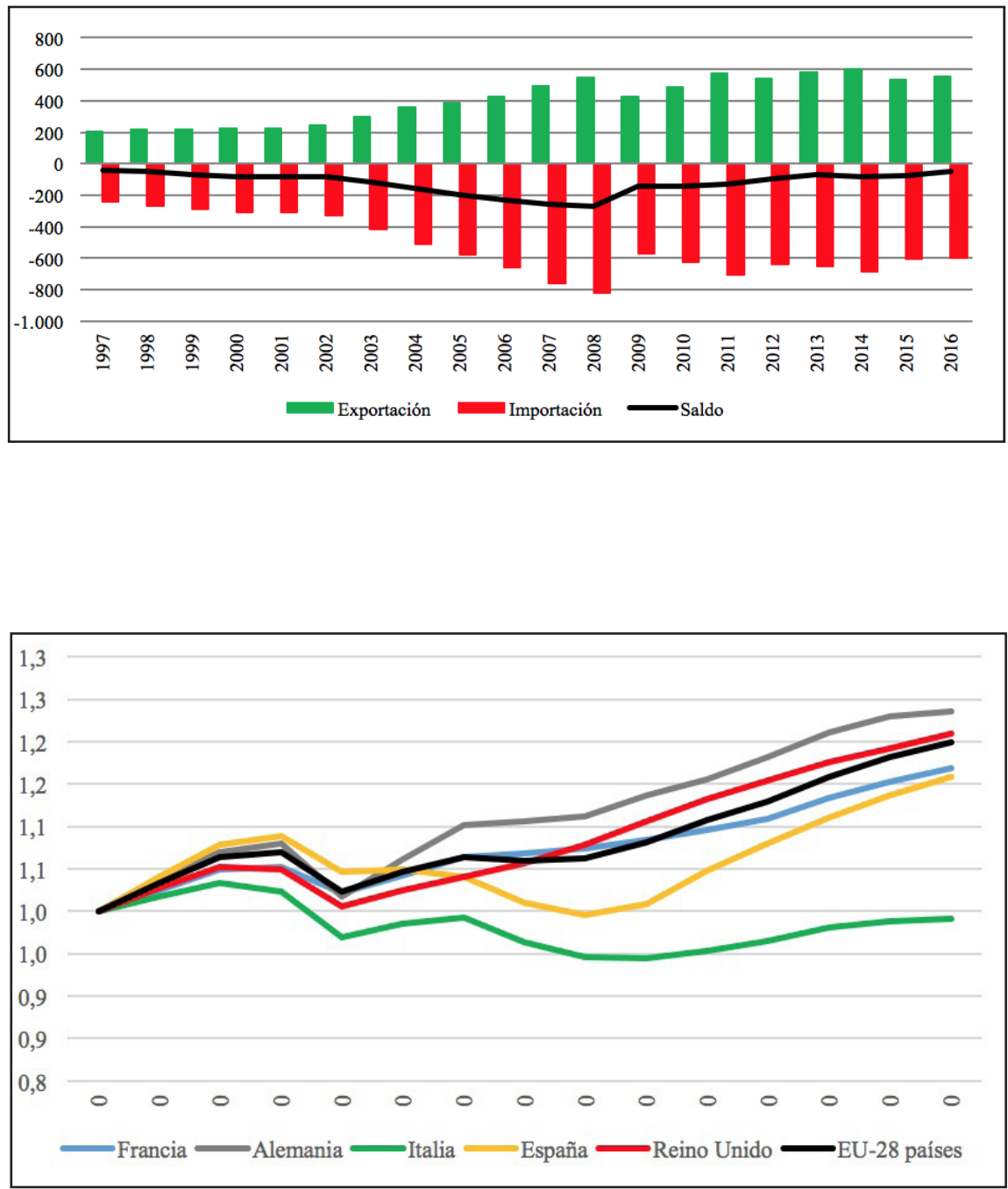

Como veremos en otro acápite, este movimiento del producto explica el ajuste y el deterioro de los indicadores sociales que, a nuestro entender, se encuentra detrás del descontento y, en parte, de los reclamos independentistas de las autoridades de la Comunidad. Pero analicemos previamente la estructura económica de Cataluña, prestando especial atención a los indicadores generales y sectores particulares de la producción.

\section{Cataluña en el Reino de España}

Cataluña tiene estatus de Comunidad Autónoma en España. Su población es de 7,44 millones de habitantes, $16 \%$ del total del país. En términos comparativos con Europa tiene poco más de la población con la que hoy cuenta Bulgaria. Luego de Andalucía es la Comunidad más poblada y es la región que recibe el mayor flujo de inmigración neto, que en 2016 registró 
24.431 inmigrantes, 7.000 más que la segunda y tercera Comunidad (Madrid y Canarias). Al revisar sus indicadores económicos y socioeconómicos, la idea de la existencia de un saqueo u opresión por parte del Estado central pierde sustento.

A nivel del producto bruto, una medida del tamaño de acumulación de capital, la región aporta $19 \%$ del total del país, lo cual está por encima de las cifras de Madrid (18,9\%) y Andalucía (13,3 \%). En 2016, esto significó aproximadamente 212.000 millones de euros, frente a los 211.000 millones de Madrid, lo que ubica a Cataluña al nivel del producto total de Grecia. Se trata, pues, de la región que produce mayor riqueza en todo el Reino de España. Podría suponerse que eso fluye hacia el rey y su corte, en una suerte de corvea acaparada por un monarca absoluto contemporáneo, trabando de esta forma el desarrollo económico y social de la Comunidad. No obstante, al escarbar mínimamente en las cifras oficiales, esta argumentación se derrumba. En principio, podemos mencionar el ingreso medio de las familias: la renta media por hogar - categoría que utiliza el Instituto de Estadísticas de España - en Cataluña es 17 \% superior al promedio nacional (figura 4).

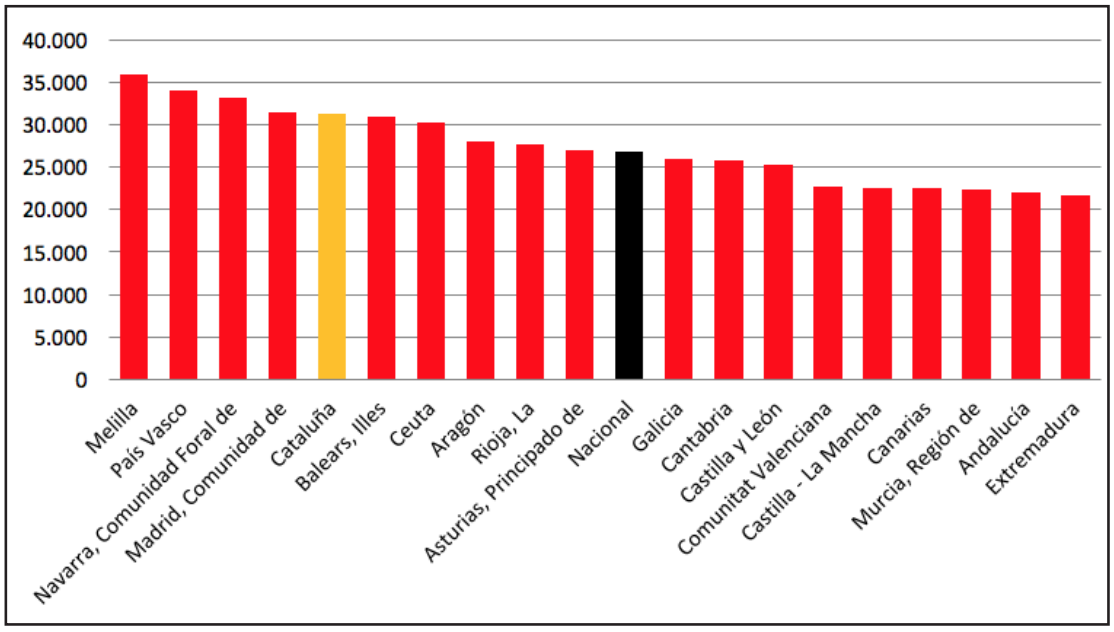

Como se observa en la figura 4, el nivel de ingreso solo es superado por estrecho margen por el País Vasco, Navarra y Madrid (el lugar de Melilla se explica porque esta es una pequeña Comunidad con solo 85.000 habitantes, por lo que la renta promedio por hogar es más elevada). En este punto, un hogar promedio catalán tiene un ingreso $44 \%$ superior al de un extremeño o andaluz, un $39 \%$ más que el de un murciano o un valenciano, $31 \%$ mayor al de las Castillas (La Mancha y León) y 20 \% más que un gallego. Así,
Figura 4.

Renta media por hogar en España por Comunidad Autónoma y nacional en 2016 (cifras en euros)

Fuente: elaboración propia con base en datos del Instituto Nacional de Estadística de España (INE). 
el nivel de hogares en la pobreza se ubica diez puntos por debajo de la media nacional (figura 5). En cuanto a la población con dificultades para llegar a fin de mes, Cataluña alcanza el 12,7 \%, similar al nivel de Madrid (12,2\%) y cuatro puntos por debajo de la media nacional.

Figura 5. Tasa de riesgo de pobreza o exclusión social por Comunidad Autónoma y nacional en España, 2016

Nota: la tasa de riesgo de pobreza es el porcentaje de población por debajo del umbral de riesgo de pobreza. La población en riesgo de pobreza mide cuántas personas tienen ingresos bajos en relación con el conjunto de la población. No mide la pobreza absoluta, sino que se trata de un indicador relativo que mide

lo que en otros países podría denominarse "desigualdad".

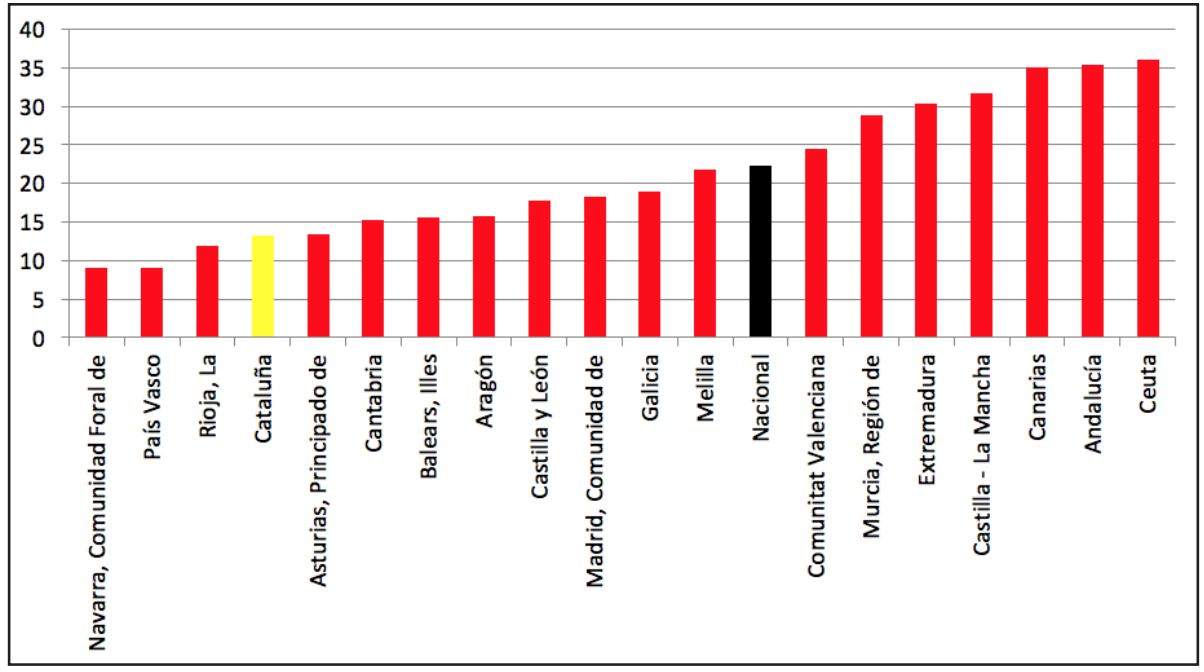

Fuente: elaboración propia con base en datos del INE.

Las variables señaladas miden el ingreso y la desigualdad en la región en términos comparativos con el resto del país. Pasemos ahora a revisar las categorías vinculadas con las remuneraciones de ocupados. En ese punto, el salario es la variable fundamental. A nivel del salario bruto anual, en la Generalitat este es $4 \%$ mayor al del promedio de la península. En la industria manufacturera, es un 7,1 \% más elevado (figura 6).

Figura 6. Salario bruto anual en la industria manufacturera en España y Generalitat de Catalunya, 2005-2015 (cifras en euros corrientes)

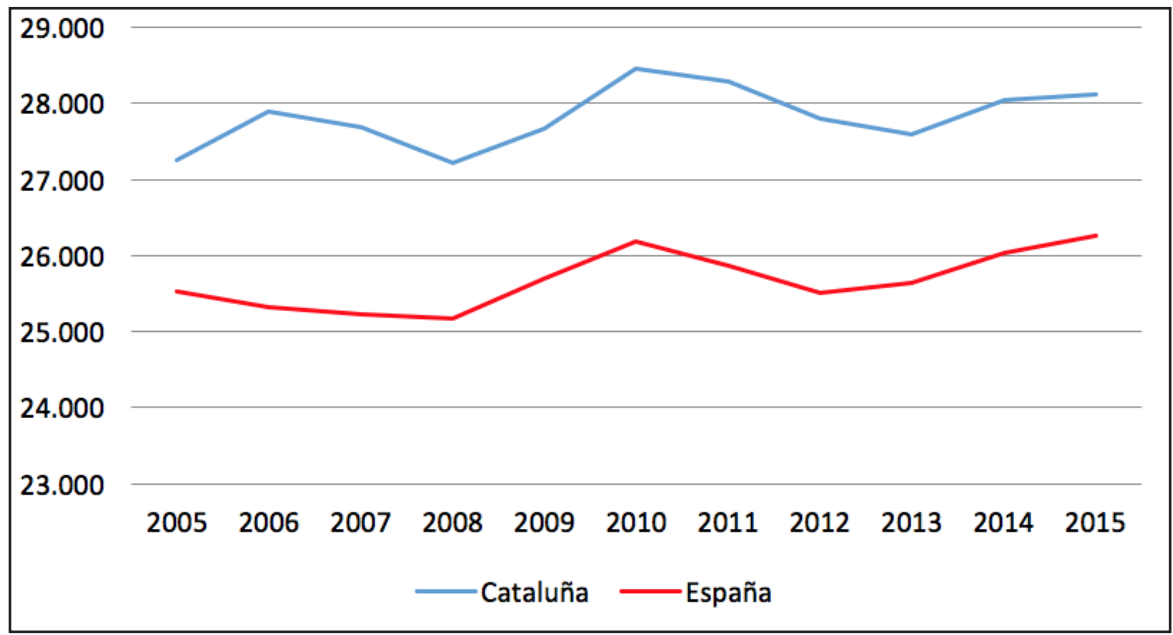


Los asalariados manufactureros catalanes tienen en promedio, como se observa en la figura 6 , un ingreso superior al de sus congéneres del resto del país. De esta breve revisión de indicadores sociales se evidencia que el nivel de vida de la población catalana guarda relación con la producción social de riqueza dentro de las fronteras españolas; es decir, el nivel de ingresos y de vida de su población se encuentra entre los más prósperos de España, junto al de otras Comunidades con niveles productivos similares (Madrid, Navarra). En este sentido, no parece haber una exacción del poder central que vaya en detrimento de los habitantes catalanes más que de otras colectividades. Por el contrario, la diferencia con las regiones más pobres (Extremadura, Galicia, Andalucía y Murcia) es considerable.

A nivel de los indicadores económicos productivos, se observa que, en contraste a lo que ocurre en el resto del país, el volumen de producción industrial en Cataluña creció 5 \% entre 2015 y 2016, traccionado principalmente por el sector energía (figura 7). Aun así, el nivel está lejos de la situación previa a 2008, mostrando que a pesar de la propaganda oficial la crisis no se superó en España. En cuanto a la estructura de las unidades productivas, las principales compañías por nivel de facturación fueron la automotriz Seat (del grupo VW-Porsche), ' Gas Natural SDG, Telecom y Cobega (el mayor embotellador de Coca Cola en el mundo, también representante de Nespresso y de otros fabricantes de bebidas). También operan desde la Comunidad, teniendo allí su sede social en España, la automotriz de origen japonés Nissan, la distribuidora eléctrica Endesa (el patrocinador de la máxima división del baloncesto español y la competición nacional más importante a nivel FIBA², la Liga ACB), las alimenticias Cargill y Nestlé, los laboratorios Nortia, Novartis y Bayer, Unilever, General Electric, las autopartistas Delphi y Lear, la electrónica Sony, la láctea Danone, la alimenticia Bunge e incluso el grupo argentino Arcor, mediante Bagley Latinoamericana S.A.

En este apartado de la industria manufacturera cabe señalar que en la región se produjo el $25 \%$ del producto manufacturero del país y el $19 \%$ del valor agregado bruto de producción total. En este punto, en cuanto a la productividad del trabajo, también se encuentra entre las principales regiones del país junto a, una vez más, Madrid y Navarra (figura 8).

\footnotetext{
El capital alemán tiene muchos representantes en la economía catalana. Entre las líderes operan Lidl, Mercedes Benz, Basf, Henkel, Boehringer Ingelheim y Beiersdorf (Nivea).

2 Federación Internacional de Baloncesto.
} 
Figura 7.

Índice de producción industrial en Cataluña y España, 2002-2016 (base $2010=1)$

Fuente: elaboración propia con base en cifras del INE.

Figura 8. Productividad de la industria manufacturera en España por Comunidad Autónoma medida como $\mathrm{PBI}$ de la manufactura en euros por asalariado, 2015

Fuente: elaboración propia con base en cifras del INE.
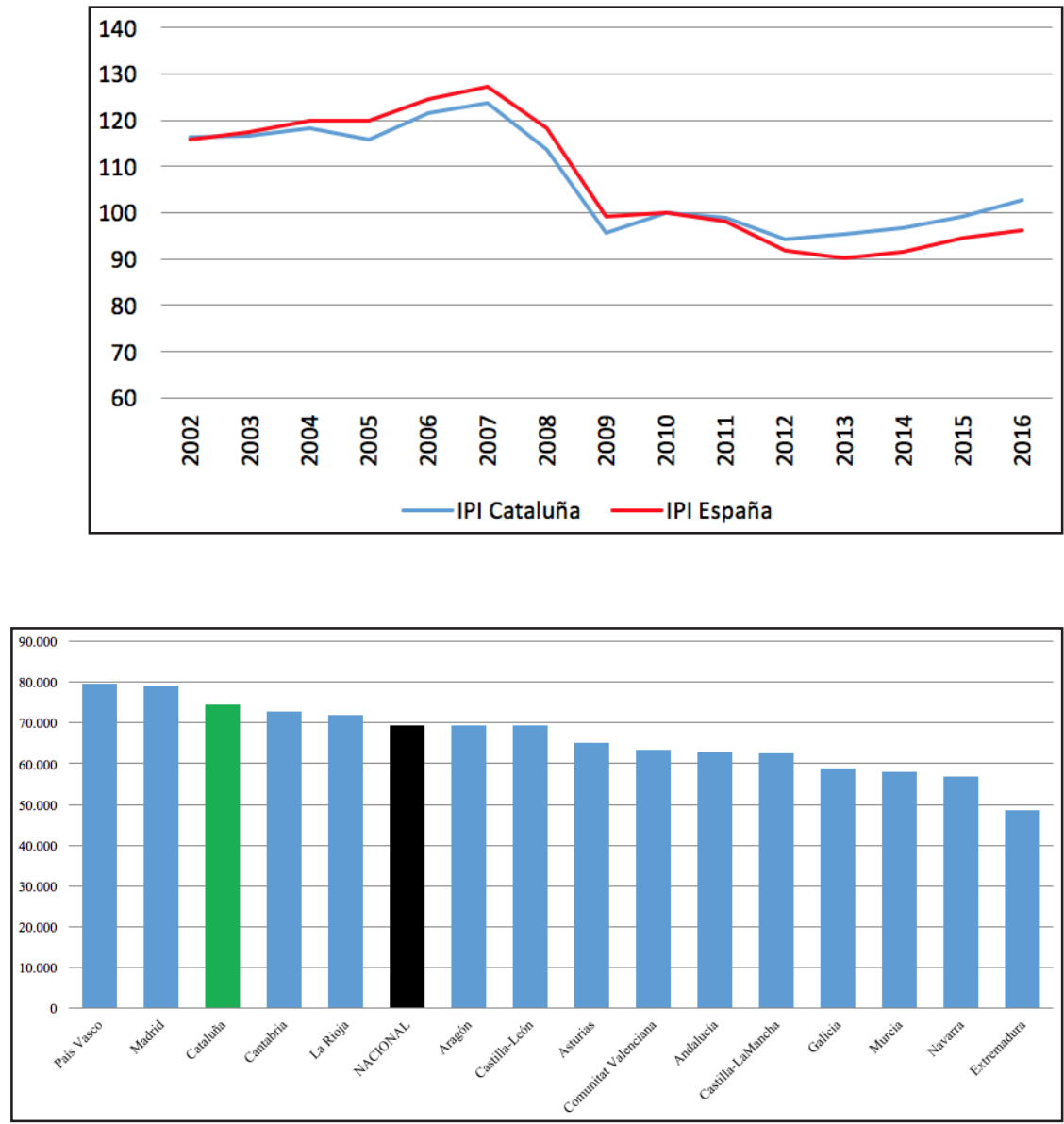

Aunque con limitaciones, la variable de producto por empleado en la manufactura es un indicador muy útil; da cuenta de la productividad, es decir, en cierta medida de la capacidad y eficiencia productiva de un sector particular (en este caso la producción industrial) en un espacio determinado (en este caso, España). De nuevo, en Cataluña se asienta buena parte de la producción industrial del país y la más avanzada en términos de la productividad del trabajo, lo que tiene su correlación en los indicadores sociales. En ese aspecto, uno de los sectores relevantes es el automotriz. Veamos algunas cifras que apoyan la argumentación que aquí desarrollamos.

\section{Apreciaciones sobre una rama productiva integrada en la región: la industria automotriz}

Un ejemplo del peso de Cataluña en la estructura económica española lo proporciona el sector automotriz. España es el segundo productor de la UE. Según datos de la cámara automotriz española, la ANFAC, en 2016 se fabricaron 2,89 millones de unidades en las 17 plantas del país. El grueso de la producción $(81 \%)$ se destina al mercado externo, en particular al resto 
de la UE. En efecto, ese año se exportaron 2,34 millones de vehículos, mientras que el mercado interno consumió solo 1,35 millones (patentamientos). En comparación, en EE. UU. se matriculan 17 millones de vehículos al año, Alemania patenta 3,8 millones, Reino Unido 2,9 e Italia 2,2. El país se encuentra por debajo del mercado mexicano, donde se registran 1,5 millones de patentamientos.

En 2017, la Generalitat representó 19,2 \% de la producción física del sector, detrás de Castilla y León $(20,4 \%)$ y delante de Galicia $(15,3 \%)$ y la Comunidad Valenciana (14,6 \%). Como señalamos, en esta región operan Seat y Nissan. En Cataluña, Mercedes Benz derivó su producción a Nissan, concentrando fabricación propia en Vitoria (País Vasco). El consorcio alemán que opera bajo Seat produce en su planta de Martorell el Audi Q3 y los Ibiza, León y Arona para el mercado mundial. Por su parte, la marca japonesa fabrica en Barcelona el modelo Pulsar y el Navarra para la UE, así como los modelos Alaskan (Renault) y el Clase X (Mercedes). Produce también el comercial NV200, con un modelo eléctrico. En lo relativo a las ventas, el mercado interno de la Comunidad es el segundo de la nación, con un 15,5 \% de los patentamientos totales en 2016 y 2017 (178.000 y 190.000 unidades, respectivamente), por detrás de Madrid, que cuenta con el $32 \%$ (367.000 y 402.000 vehículos), y por encima de los valores de Andalucía y la Comunidad Valenciana, ambas con $11 \%$ de las ventas internas (126.000-139.000 vehículos). Para 2017, el parque automotor (turismos, comerciales y buses) superaba las 4,38 millones de unidades, un 15,2 \% del total nacional.

La información disponible del Instituto de Estadística de Catalunya (IDESCAT) nos permite señalar algunos elementos para describir no solo la importancia de esta actividad en la región sino también enumerar algunos elementos vinculados a la integración productiva Cataluña-España. La fabricación de vehículos de motor, remolques y semirremolques se ubicó en 2017 como la segunda rama productiva con mayor nivel de ventas de la región (17.700 millones de euros), por detrás de la alimenticia y apenas superior a la industria química. Un $30 \%$ de esas ventas se dirigieron al mercado interno, $60 \%$ al resto de Europa y el valor restante a otros países del mundo (IDESCAT, 2017). Si agregamos el sector de autopartes, donde se destaca la fabricación de motores y accesorios eléctricos y de otros componentes, se añaden 7.665 millones de euros más en ventas para empresas afincadas en la Comunidad, de las cuales 50,8 \% fueron consumidas en España, 39,6 \% en otros países de la UE y 9,6 \% en el resto del mundo. Cabe mencionar que las 
compras que realizan tanto la industria auxiliar como el sector terminal para poder realizar su operatoria cotidiana se dividen casi exactamente en partes iguales entre compras al interior del país y del exterior (datos del IDESCAT con base en el INE).

En resumen, este somero relevamiento de datos posibilita ver que, a pesar de que a nivel nacional el sector automotriz es una industria básicamente de exportación, se verifica una considerable integración entre la región y el resto del mercado español. Esta situación plantea dudas sobre la viabilidad económica o productiva de una Cataluña libre en el mediano plazo, como señalan algunos académicos (Bosch \& Espassa, 2014). ${ }^{3}$ Incorporando el resto de las actividades industriales, la relación se vuelve más estrecha: en 2017, el 65,1 \% del valor de las ventas se realizaron dentro del país, $24,5 \%$ en la UE y $10,4 \%$ en el resto del mundo (figura 9).

Figura 9. Valor de ventas de industrias de Cataluña por destino en 2017 (cifras en millones de euros)

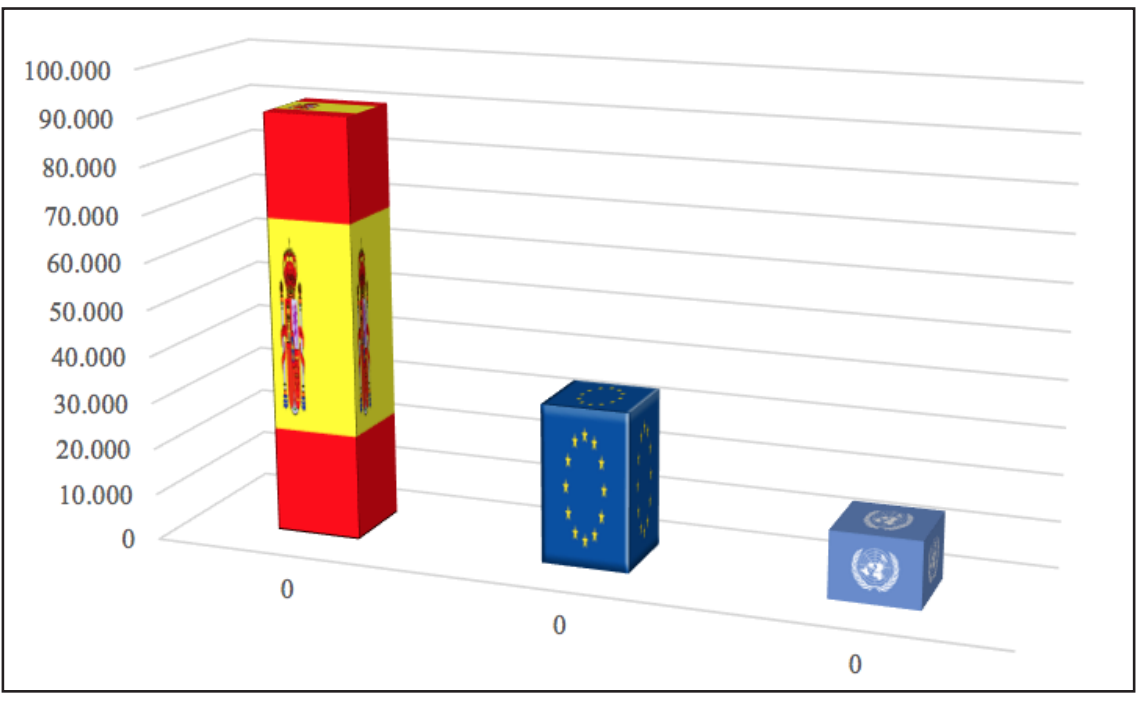

La evaluación de los indicadores nos muestra que Cataluña es una porción de un espacio nacional donde el capital acumula sin trabas. Más aún, es la región más rica de España, lo cual se traduce en cierta medida en los niveles de ingreso y condiciones de vida de su población, superiores a las del promedio nacional. Entendemos que el problema de la región no hay que buscarlo en el rey, sino en la crisis capitalista global.

3 Este debate sobre la viabilidad económica merece un análisis más detallado que incorpore mayor número de variables (fiscales, financieras y del orden de lo político, en relación con la posibilidad de permanecer o ser excluida de la UE, en caso de que Cataluña consiga una hipotética independencia), lo cual excede los límites de este trabajo. Recomendamos al lector revisar los citados trabajos de Bosch y Espassa (2014) para una respuesta positiva a este debate, así como el trabajo de Feito-Higuerela (2014) para una negativa. 


\section{LA CRISIS ES DEL CAPITAL}

Intentonas independentistas, triunfos de "outsiders" y reaparición de partidos filofascistas en varios lugares de Europa e incluso del resto del mundo. La situación catalana es parte de ello, del largo proceso que abre la crisis del capitalismo. En el caso español, se expresó en su mayor magnitud en 2008 con la recordada debacle de las hipotecas, que en ese momento arañaban los 1,3 millones de deudores, por un estimado de 206.000 millones de euros. Entre ese año y 2013, el PBI acumuló un retroceso real de casi $10 \%$ (medido en dólares de 2010). En Cataluña, la caída fue de $11 \%$. Recién en 2016 recuperó valores similares a los de 2008.

Cabe señalar que España tiene una balanza comercial deficitaria que no llega a ser cubierta por rubros como el turismo. Para afrontar el nivel de gastos, desde mediados de los años 90, el país recurre de forma creciente al endeudamiento. Si bien hasta fines de 2008 la deuda pública total se mantuvo en un modesto $39 \%$ del PBI por el auge de la actividad económica, con la recesión de 2009 esta relación comenzó a incrementarse (figura 10).

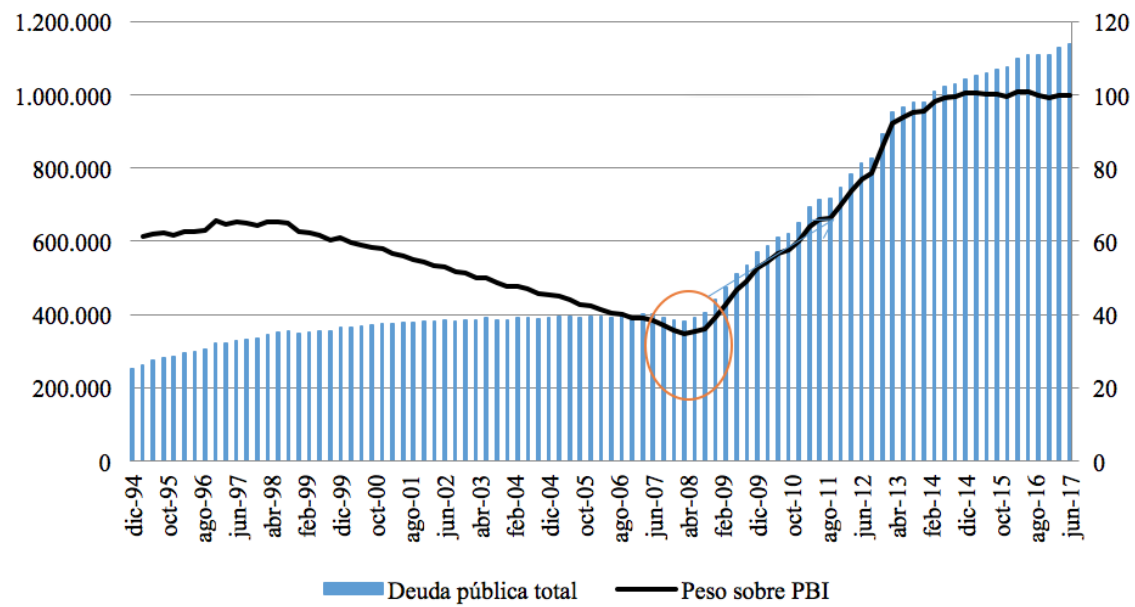

Para mediados de 2017, la deuda pública de España prácticamente igualaba su PBI (1.137 billones de euros). A nivel de actividad económica, la crisis dejó sus huellas: la actividad industrial se ubicó $17 \%$ por debajo de los volúmenes del año 2008 y todavía un 4 \% por debajo de 2010. Según datos oficiales, de enero de 2009 a junio de 2017 la construcción cayó $25 \%$. El desempleo trepó oficialmente a 18 \% (casi cuatro millones de personas), el doble con respecto a enero de 2008, con cifras alarmantes en Castilla-La
Figura 10.

Deuda pública total de España (eje izquierdo) y peso sobre el PBI (eje derecho), diciembre de 1994 a junio de 2017 (cifras en millones de euros corrientes)

Fuente: elaboración propia con base en cifras del INE y el Banco Central Europeo. 
Figura 11. Tasa de desempleo oficial de mayores de 16 años en

España y Comunidades seleccionadas, 2006-2017

Fuente: elaboración propia con base en cifras del INE.

Figura 12a. Evolución del salario real y de la productividad laboral en España y Cataluña, 20022015 (base $2002=1$ )

Fuente: elaboración propia con base en cifras del INE.
Mancha (22,3\%), Andalucía (26,1\%) y Extremadura (27,5 \%). En Cataluña, si bien menor, se mantuvo en un nivel alto: $15,7 \%$. La tasa se dispara entre los jóvenes de $15-24$ años, con un 44,4 \%, siendo el $5^{\circ}$ país en el mundo con la desocupación juvenil más alta (figura 11). Estas circunstancias también presionaron sobre el gasto público, el cual se expandió desde 2009.

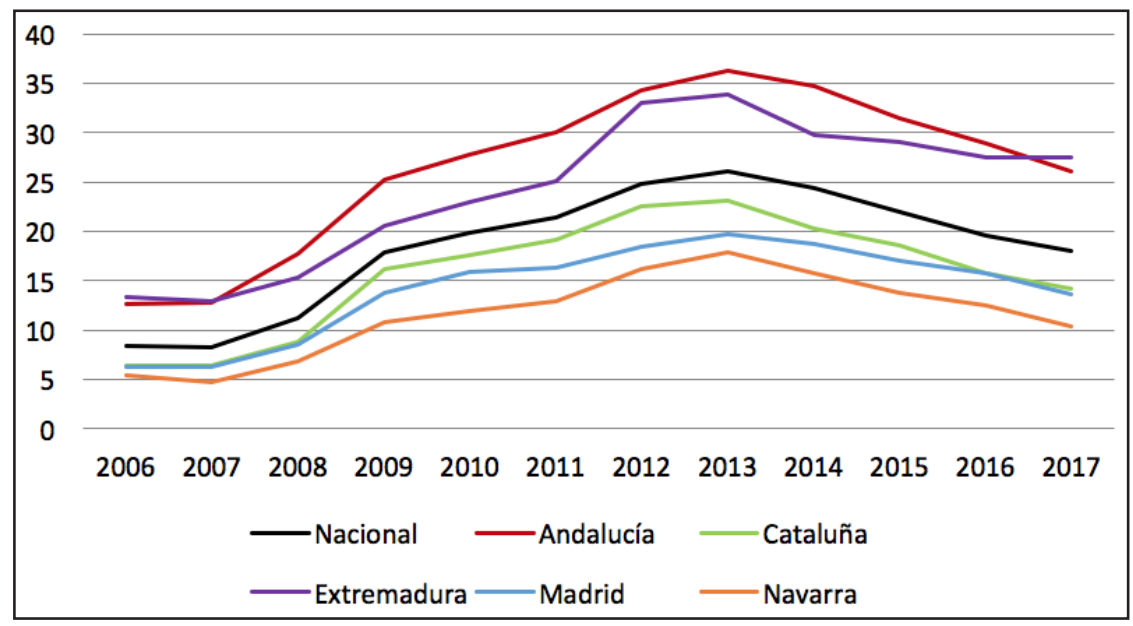

En estas circunstancias, y ante dificultades políticas, Rajoy no pudo implementar medidas más profundas de ajuste al nivel que solicitaban los miembros de la UE. El déficit fiscal todavía estaba en 4 puntos del PBI. La vía que encontró el capital para sostener la actividad luego del 2008, además de la deuda y cierto nivel de ajuste, fue el aumento de la productividad y la caída del salario real. Mientras la productividad general incrementó $8 \%$ y un $14 \%$ en la industria entre 2010 y 2014, el salario bruto real cayó 6 \% en España y $9 \%$ en Cataluña (figura 12 a y b).

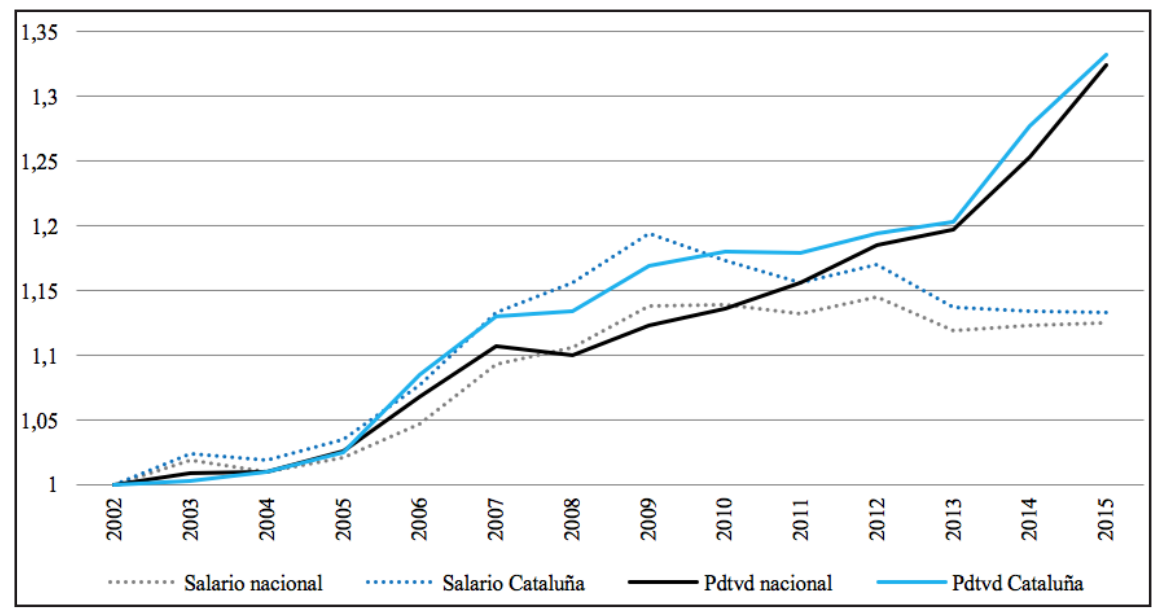




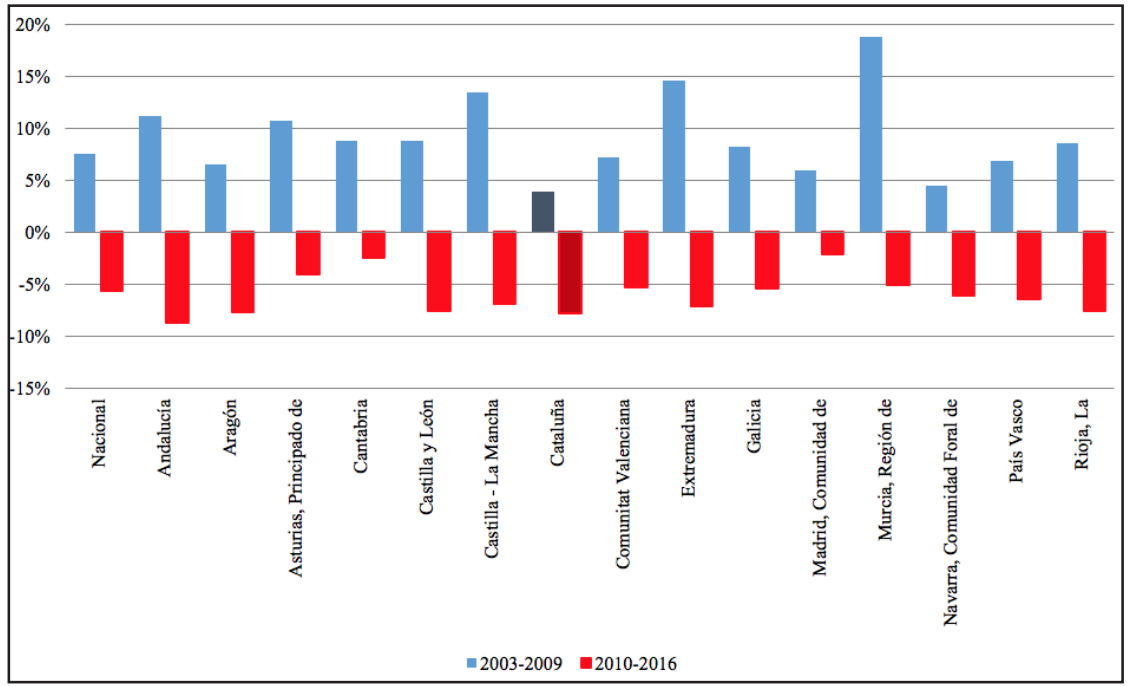

Este cuadro se completa con los indicadores de ingresos, los cuales empeoraron desde la crisis. En este caso, la renta media real de los hogares retrocedió un 17,8 \% a escala nacional en el período 2009-2016, 20 \% en Madrid y $14 \%$ en Cataluña (figura 13).

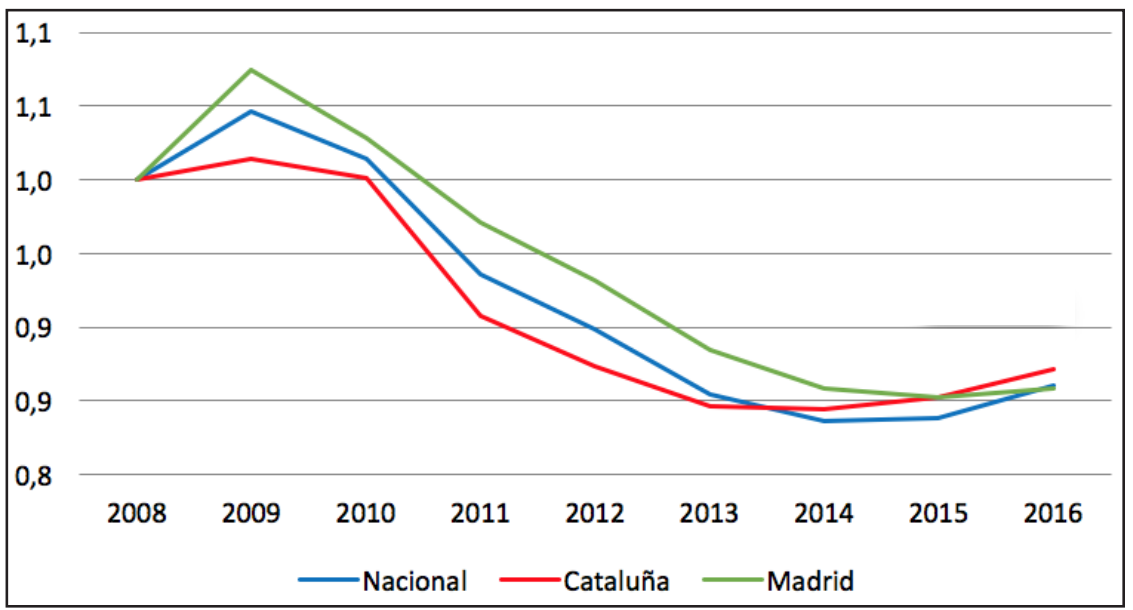

En ese sentido, registramos un incremento considerable en la tasa de explotación. A partir de un aproximado de este indicador, dividiendo el excedente de explotación sobre la masa salarial, comprobamos que este incrementó casi $50 \%$ en solo 5 años (figura 14). Esto no es novedoso, sino que se relaciona con períodos previos de la historia española, sobre todo durante la segunda mitad del siglo XX, como destaca Guerrero (2006b).
Figura $12 b$.

Evolución del salario real entre 2003-2009 y 2010-

2016 en España y sus

Comunidades Autónomas

Fuente: elaboración propia con base en cifras del INE.

Figura 13.

Evolución de la renta media de hogares en España y las Comunidades de Madrid y Cataluña, 2008-2016 (base $2008=1$ )

Fuente: elaboración propia con base en cifras del INE. 
Figura 14. Tasa de explotación del trabajo en la industria manufacturera en España, 2010-2015

Nota: corresponde al cociente entre excedente de explotación bruto sobre remuneración de asalariados.

Fuente: elaboración propia con base en cifras del INE.

Productividad (medida como valor agregado bruto [VAB] por hora trabajada, en euros) en la industria manufacturera en países seleccionados de la UE (eje izquierdo) y diferencia porcentual de España con respecto a Alemania (eje derecho), 1995-2016

Fuente: elaboración propia en base a AMECO y Eurostats.

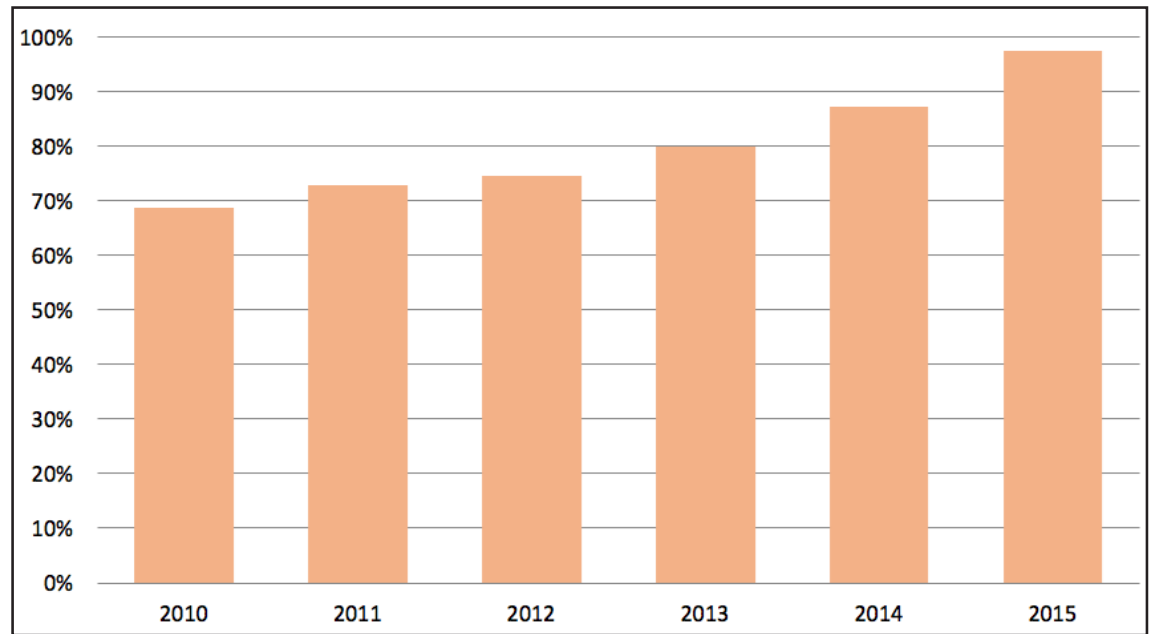

Estos últimos dos cuadros son bastantes significativos: la recuperación parcial de la crisis (aun sin alcanzar los niveles de actividad previos) se está dando mediante el avance del capital sobre las condiciones generales de vida de los trabajadores, con aumento de la explotación y caída del salario real. La salida que aquí busca el capital es más explotación y peores condiciones. Pero la tarea realizada hasta ahora por el capital en España parece insuficiente: corre muy por detrás de las economías que marcan el ritmo de la zona euro, como Alemania y Francia, en términos de productividad del trabajo (figura 15).

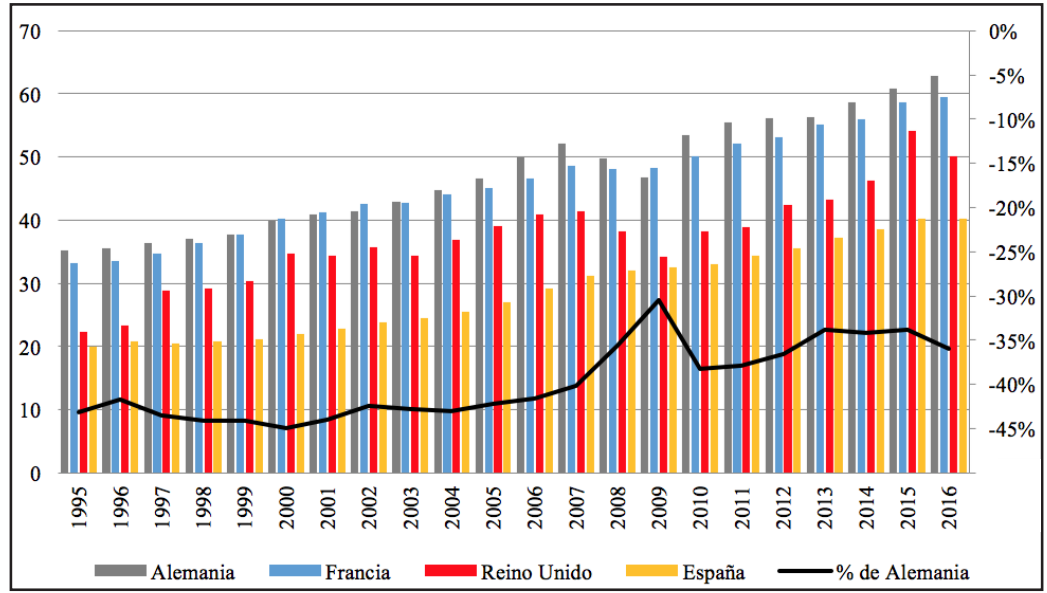

La situación, por el momento, no suscita ninguna respuesta enérgica de los trabajadores, sino, por el contrario, el fortalecimiento de variantes burguesas como la impulsada por los secesionistas catalanes. 


\section{REFLEXIONES FINALES}

En este trabajo repasamos la evolución de indicadores económicos generales e indicadores de carácter socioeconómico y por sectores productivos tanto de España como de Cataluña durante los últimos 20 años, con especial atención a la etapa que se abre a partir de la crisis de 2008-09. El objetivo fue estudiar la estructura general y las condiciones de vida y de ingreso de la población catalana con respecto a otras comunidades autónomas y al promedio nacional, con el fin de discutir la idea de una "opresión" por parte del gobierno central sobre la región.

Encontramos que Cataluña es una de las regiones más ricas del país en términos productivos y económicos y que sus habitantes tienen un nivel de vida muy superior al promedio nacional. No se constata en este relevamiento una exacción que impida el desarrollo de la región favoreciendo a otras. Las demandas del personal político catalán parecen estar vinculadas a lograr un mejor tratamiento fiscal en el contexto de la caída de recursos y de un alto endeudamiento. A nivel de la producción, observamos con el estudio de la rama automotriz que la región tiene un importante nivel de integración con el resto del mercado español.

Al estudiar someramente la situación que se abre con la crisis de 2008, encontramos que toda la nación ve deteriorar sus indicadores generales, de ingreso y laborales. Cataluña no será la excepción, aunque siempre manteniendo distancia con el promedio nacional. Aquí, la monarquía no es el problema. El trasfondo se relaciona con la crisis, la cual afecta las condiciones socioeconómicas de la masa de la población. En este escenario, y no solo en España, burguesías marginales y sus representantes políticos apelan a discursos de fragmentación para disputar con otras fracciones lo que "ceden" por la transferencia a regiones más pobres del mismo país mediante el sistema fiscal. En esa disputa, los trabajadores no tienen ninguna propuesta por la positiva. En la crisis, una hipotética escisión no mejoraría sus condiciones, sino que posiblemente los expulsaría del Euro (al menos hasta que lograra reinsertarse como miembro), posibilitando devaluar y deprimir aún más el salario real y perdiendo la hacienda regional y el financiamiento del Banco Central Europeo (BCE).

Un escenario posible podría ser que el desmembramiento facilite al capital más poderoso de la zona, el alemán (que mantiene saldo comercial superavitario con España/Cataluña), reorganizando la situación en el proceso de concentración en Europa. Los obreros de lo que quede de España, 
más empobrecidos, serán mano de obra barata para el gran capital, lo que en mediano plazo podría también ser el destino de los catalanes. Si ya una economía que es un tercio de la alemana tiene serias dificultades en la competencia europea, un país cinco veces menor, manteniendo una estructura similar, tiene pocas oportunidades si no ajusta sus indicadores (o sea, el nivel de vida). Más allá del parasitismo de la monarquía, el problema está en otro parásito peor: la clase dominante, que convierte a las masas en la carne de cañón de sus disputas. Pero este planteamiento ya es parte de futuros escritos. 


\section{REFERENCIAS}

\section{Bases de datos}

Atlas Comercio Internacional MTI. http://atlas.media.mit.edu/en/visualize/ tree_map/hs92/export/esp/all/show/2016/

AMECO, Base macroeconómica de la Unión Europea. https://ec.europa.eu/ economy_finance/ameco/user/serie/SelectSerie.cfm

Banco Central Europeo. https://www.ecb.europa.eu/ecb/legal/1005/6511/ html/index.es.html

Bureau of Labor Statistics. www.bls.gov

Eurostat, Base de datos de la Oficina Estadística de la Unión Europea. https:// ec.europa.eu/eurostat/home?

Institut d'Estadística de Catalunya (IDESCAT). https://www.idescat.cat/

Instituto Nacional de Estadística de España (INE). https://ine.es/

OCDE Stats. https://stats.oecd.org/

\section{Referencias bibliográficas}

Alonso-Pérez, M., \& Furió-Blasco, E. (2010). La economía española. Del crecimiento a la crisis pasando por la burbuja inmobiliaria. Cahiers de civilisation espagnole contemporaine, 6, 1-19.

Antenas, J. (2012). La indignación, tras la explosión inicial. El 15M en Catalunya durante 2012. Anuari del Conflicte Social 2012, 2, 263-274.

Antenas, J., \& Vivas, E. (2014). Impacto de la crisis en el derecho a una alimentación sana y saludable. Informes SESPAS 2014. Gaceta Sanitaria, 28(51), 58-61. https://doi.org/10.1016/j.gaceta.2014.04.006

Araceli-Mateos, A. (2013). España: crisis y recortes. Revista de ciencia política, 33(1), 161-183. https://doi.org/10.4067/S0718-090X2013000100008

Asociación Española de Fabricantes de Automóviles y Camiones [ANFAC]. (2017). Informe Anual 2017. ANFAC.

Bosch, N., \& Espassa, M. (2014). La viabilidad económica de una Cataluña independiente. Revista de Economía Aplicada, XXII(64), 135-162.

Buendía, L. (2018). The Spanish economic 'miracle' that never was. En O. Parker \& D. Tsarouhas (eds.), Crisis in the Eurozone periphery. The political economies of Greece, Spain, Ireland and Portugal. Pallgrave McMillan. https://doi.org/10.1007/978-3-319-69721-5_3 
Cebrián, J., Bodega, M., Martín-Lou, M., \& Guajardo, F. (2010). La crisis económica internacional y sus repercusiones en España y en su población inmigrante. Estudios Geográficos, 71(268), 67-101. https://doi. org/10.3989/estgeogr.0505

Chakri, F. (2014). Tasa de beneficio y distribución del ingreso en la economía española (1964-2012). Ensayos de economía, 44, 75-99.

Clua-Losada, M. (2018). The unfolding of Spain's political crisis: from the squares to the ballot box. En O. Parker \& D. Tsarouhas (eds.), Crisis in the Eurozone Periphery. Building a Sustainable Political Economy: SPERI Research \& Policy (pp. 141-160). Palgrave Macmillan. https://doi. org/10.1007/978-3-319-69721-5_7

Domingo-i-Vals, A., Sabater-i-Coll, A., \& Ortega-Rivera, E. (2014). ¿Migración neohispánica? El impacto de la crisis económica en la emigración española. Empiria, 29, 39-66. https://doi.org/10.5944/empiria.29.2014.12940

Dumenil, G. (2012). En la actual crisis de hegemonía financiera, los capitalistas como "aprendices de brujo" perdieron el control y todo se incendió. Análisis Económico, XXVII(66), 353-369.

Feito-Higueruela, J. L. (2014). Razones y sinrazones económicas del independentismo catalán. Panel Cívico.

Fontana, J. (2014). La formació d'una identitat. Epub-Cat.

Freeman, A. (2016). Booms, depressions, and the rate of profit: a pluralist, inductive guide. En T. Subasat \& J. Weeks (eds.), The great meltdown of 2008: Systemic, conjunctural or policy-created? (pp. 73-94). Edward Elgar Publishing Limited.

Gallo, P., \& Gené-Badia, J. (2015). Evidencias y reflexiones sobre el impacto de la crisis en la salud y la sanidad. Panorama Social, 22, 79-92.

García-Montalvo, J. (2009). Financiación inmobiliaria, burbuja crediticia y crisis financiera. Lecciones a partir de la recesión de 2008-09. Papeles de economía española, 122, 66-85.

Guerrero, D. (marzo de 2006a). La traición de clase de la izquierda nacionalista en España y su impacto sobre la economía española. X Jornadas de Economía Crítica, Madrid, España.

Guerrero, D. (2006b). Explotación de los asalariados y ganancia capitalista en España (1954-2001). Razón y Revolución, 16, 23-56. 
Gutiérrez, A., \& Delclós, X. (2014). Migraciones residenciales en Cataluña (2003-2012). ¿Cambios de pautas a partir de la crisis económica? XIV Congreso Nacional de Población, Sevilla, España.

Gutiérrez, A., \& Delclós, X. (2015). ¿Hipertrofia inmobiliaria? Análisis de las pautas territoriales del boom e implicaciones del estallido de la burbuja en Cataluña. Cuadernos Geográficos, 54(1), 283-306.

Gutiérrez, A., \& Delclós, X. (2017). Geografía de la crisis inmobiliaria en Cataluña: una lectura a partir de los desahucios por ejecución hipotecaria. Scripta Nova, XXI(557), 2-33. https://doi.org/10.1344/sn2017.21.17734

Gutiérrez, A., \& Vives-Miró, S. (2018). Acumulación de viviendas por parte de los bancos a través de los desahucios: geografía de la desposesión de vivienda en Cataluña. EURE, 44(132), 5-26. https://doi.org/10.4067/ s0250-71612018000200005

Guzmán-Ramírez, A., \& Quiroga-Riviere, M. (2013). La crisis económica y el movimiento independentista catalán. Oasis, 18, 55-71.

Harvey, D. (2016). Crisis theory and the falling rate of profit. En T. Subasat \& J. Weeks (eds.), The great meltdown of 2008: Systemic, conjunctural or policy-created? (pp. 37-54). Edward Elgar Publishing Limited.

Kliman, A. (2015). Harvey versus Marx on Capitalism's Crises Part 1: Getting Marx Wrong. http://www.newleftproject.org/index.php/site/article_ comment/harvey_versus_marx_on_capitalisms_crises_part_1_getting_marx_wrong

Llorca-Asensi, E. (2015). El desafío catalán. Un análisis descriptivo. Revista Castellano-Manchega de Ciencias Sociales, 20, 45-60. https://doi. org/10.20932/rbcs.v0i20.11

López, M., Rodríguez, A., \& Agudelo, J. P. (2010). Crisis de la deuda soberana en la Eurozona. Perfil de Coyuntura Económica, 15, 33-58.

López-Villanueva, C., García-Coll, A., Bretones, M., \& Crespi-Vallbona, M. (2017). Los efectos de la crisis económica en el urbanismo disperso de la Región Metropolitana de Barcelona. Clitvage, 5, 290-331.

Maito, E. (2014). La transitoriedad histórica del capital. La tendencia descendente de la tasa de ganancia desde el siglo XIX. Razón y Revolución, 26, 129-159.

Mateo-Tomé, J. (2019). The theory of crisis and the great recession in Spain. Pallgrave. https://doi.org/10.1007/978-3-030-27084-1 
Molinero, C., \& Ysás, P. (2014). La cuestión catalana. Cataluña en la transición española. Crítica.

Moseley, F. (2013). The U.S. economic crisis: from a profitability crisis to an overindebtedness crisis. Review of Radical Political Economics, 45(4), 472-477. https://doi.org/10.1177/0486613412475187

Roberts, M. (2009). The great recession. profit cycles, economic crisis. A Marxist view. Lulu.

Roberts, M. (2016). The long depression. Haymarket Books.

Rocha, F., \& Aragón, J. (2012). La crisis económica y sus efectos sobre el empleo en España. Gaceta Sindical, 19, 67-90.

Ruipérez-Alamillo, J. (2013). La nueva reivindicación de secesión de Cataluña en el contexto normativo de la Constitución Española de 1978 y el Tratado de Lisboa. UNED, Teoría y Realidad Constitucional, 31, 89-135. https://doi.org/10.5944/trc.31.2013.10304

Sanromá-Meléndez, E. (2012). El mercado de trabajo español en la crisis económica (2008-2012). Revista de Estudios Empresariales. Segunda Época, 2, 29-57.

Sartelli, E. (2006). Debates sobre la crisis capitalista. Un mal comienzo. A propósito de la crítica de Rolando Astarita. Razón y Revolución, 15, 209224.

Serra, M., Ubasart-González, G., \& Marti-I-Puig, S. (2018). Cataluña y la triple crisis española. Nueva Sociedad, 273, 22-32.

Taguas, D. (2013). Las fuerzas públicas españolas en el inicio del siglo XXI: los efectos de la crisis financiera de 2007. Fundación de Estudios Financieros.

Torrero-Mañas, A. (2008). La crisis financiera internacional y económica española. Encuentro.

Verd-Pericás, J., \& López-Andeu, M. (2016). Crisis del empleo y polarización de las trayectorias laborales. El caso de los adultos jóvenes en Cataluña. Papers Revista de Sociología, 101(1), 5-30. https://doi.org/10.5565/rev/ papers. 2167 